\title{
PENGARUH KUALITAS JASA, CITRA PERUSAHAAN DAN TINGKAT SUKU BUNGA KREDIT TERHADAP KEPUTUSAN PENGAMBILAN PRODUK KREDIT MIKRO
}

\author{
Hengki Mangiring Parulian Simarmata \\ (Politeknik Bisnis Indonesia)
}

\begin{abstract}
Abstrak
Penelitian ini bertujuan untuk mengetahui pengaruh kualitas jasa, citra perusahaan dan tingkat suku bunga kredit terhadap keputusan pengambilan kredit mikro studi kasus pada Bank Perkreditan Rakyat Karyajatnika Sadaya Bandung. Penelitian yang dilakukan merupakan penelitian deskriptif dan verifikatif. Sampel yang digunakan adalah 110 nasabah dari delapan kantor cabang mikro BPR KS Bandung. Uji Hipotesis yang digunakan dengan Structural Equation Model (SEM) untuk mengetahui pengaruh kualitas jasa, citra perusahaan dan tingkat suku bunga kredit terhadap keputusan pengambilan kredit mikro baik secara parsial maupun secara simultan. Hasil penelitian menunjukkan bahwa tanggapan responden mengenai kualitas jasa dinilai baik, Citra BPR KS juga dinilai sudah baik oleh konsumen. Sedangkan tingkat suku bunga yang ditawarkan rendah atau dapat diterima oleh nasabah. Hasil pengujian model menunjukkan adanya pengaruh positif dan signifikan antara kualitas jasa dan citra perusahaan terhadap pengambilan kredit mikro, sedangkan untuk suku bunga memiliki pengaruh negatif terhadap keputusan pengambilan kredit mikro.Untuk pengembangan peneliti berikutnya dapat dilakukan penelitian yang sama di daerah yang lingkungan dan budaya memiliki karakteristik yang berbeda atau dengan perubahan variabel dimana variabel loyalitas atau variabel customer relationship management dapat dikembangkan pada model penelitian di masa mendatang
\end{abstract}

Kata Kunci : Kualitas Jasa, Citra Perusahaan, Tingkat Suku bunga, Pengambilan Keputusan Konsumen

\section{PENDAhuluaN}

Latar Belakang

Perbankan memiliki peranan yang sangat penting dalam pertumbuhan ekonomi sebuah bangsa karena peranannya dalam jasa keuangan mampu menggerakan perekonomian bangsa. Perkembangan lembaga keuangan menjadi sebuah petanda semakin butuhnya dunia usaha akan jasa keuangan dan modal. Modal yang diperoleh masyarakat berasal dari perorangan atau lembaga keuangan misalnya Bank Umum, Bank Syariah, Bank Perkreditan Rakyat, Pegadaian dan Koperasi.BPR merupakan lembaga perbankan resmi yang diatur berdasarkan Undang-Undang No. 7 tahun 1992 tentang Perbankan dan sebagaimana telah diubah dengan Undang-Undang No. 10 tahun 1998 (www.bi.go.id, 2013)

Perkembangan BPR akhir-akhir ini tidak semulus seperti yang diharapkan, seiring dengan persaingan dunia perbankan yang kian ketat dan berbagai kebijakan yang dikeluarkan oleh Bank Indonesia untuk penyaluran kredit mikro, BPR harus bekerja keras untuk bersaing dan meningkatkan kegiatan bisnisnya (www.infobanknews.com, 2013). Berdasarkan data Bank Indonesia dan Badan Pusat Statistik jumlah perkembangan kantor cabang Bank Umum di Jawa Barat 392 kantor, Bank Syariah 27, BPR 793 dan Koperasi 23,848 yang terdiri 589 KUD dan 23.259 koperasi non KUD (www.bi.go.id, 2013 ; BPS, 2013:417).

Tabel 1 Jumlah BPR Konvensional Berdasarkan Badan Hukum di Provinsi Jawa Barat (2009-2013)

\begin{tabular}{|c|c|}
\hline Tahun & Jumlah BPR \\
\hline 2009 & 398 \\
\hline 2010 & 376 \\
\hline 2011 & 325 \\
\hline
\end{tabular}




\begin{tabular}{|c|c|}
\hline 2012 & 307 \\
\hline Juli 2013 & $\mathbf{3 0 5}$ \\
\hline
\end{tabular}

Sumber : www.bi.go.id, Statistik Perbankan Indonesia Vo.11 No.7 Juni 2013

Data Bank Indonesia setiap tahunnya menunjukkan jumlah BPR semakin turun. Dengan adanya kebijakan Bank Indonesia (PBI) 14/22/PBI/2012 menyebut portopolio Bank Umum sebesar $20 \%$ harus dipergunakan untuk pembiayaan UMKM menyebabkan BPR harus berjuang keras agar mampu bersaing. Jika dibandingkan dengan Bank Umum tentulah BPR jauh dari segi kualitas jasa, citra dan suku bunga kredit. Dengan karakteristik BPR yang memiliki kemudahan dalam penyaluran kredit dengan prinsip tepat waktu, tepat jumlah dan tepat sasaran dan lebih dekat dengan masyarakat menjadikan BPR masih diminati nasabah.

Persaingan yang ketat didalam indutri perbankan memaksa perusahaan untuk mendesign ulang strategi bisnis dan pemasaran untuk mempertahankan atau meningkatkan keunggulan bersaing (Putra, 2013:448). Perusahaan jasa atau bank harus mengenali bahwa agar bersaing lebih efektif, bank harus menunjukkan keunggulan produk mereka (Putra, 2013:490), memberikan kualitas yang lebih baik dari layanan pesaing makan perusahaan akan memiliki kemungkinan untuk sukses lebih besar (Kumar, 2013:3). Bank yang memiliki basis pelanggan yang terbesar dan tingkat pelanggan yang setia akan menjadi pemimpin pasar di industri perbankan (Kumar, 2013:1).

Kualitas jasa yang dirasakan akan menjadi keunggulan kompetitif untuk menarik pelanggan baru dan memberikan kontribusi untuk pangsa pasar (Junaid - ul - haq, Abrar \& Nasir 2013:246; Hasan et al, 2013:301). Jika pelanggan puas maka dia akan melakukan pembelian ulang dan membeli lebih banyak, merekomendasikan produk kepada orang lain dan akan loyal kepada merek (Andronikidis, 2009:6; Liu \& Chen, 2013:159) sehingga mereka kurang sadar akan harga dan memiliki pengalaman yang baik dengan perusahaan (Junaid - ul - haq, Abrar \& Nasir, 2013:246).

Proses evaluasi konsumen muncul setelah mengetahui citra perusahaan (Lin \& Lu, 2010:17; Junaid - ul - haq, Abrar \& Nasir, 2013:247) dan memainkan peran penting dalam mempengaruhi prilaku konsumen (Chattananon, et al, 2008:350; Rattanaphan, 2012:290). Kebanyakan konsumen akan mengevaluasi keseluruhan hubungan dengan perusahaan dari jenis produk atau jasa yang ditawarkan, karena citra merupakan kekuatan persepsi konsumen dalam pikirannya ketika mendengar nama perusahaan. Citra perusahaan yang baik akan memberikan kepercayaan dan kredibilitas kepada konsumen atau pembeli industri (Amini et al, 2012:197). Banyak para peneliti di bidang pemasaran telang mengakui bahwa citra perusahaan menjadi faktor dominan didalam prilaku pembelian konsumen (Weiwei, 2007: 57)

Bank Perkreditan Rakyat Karyajatnika Sadaya sebagai BPR yang berkedudukan di Bandung menjadi bagian dari persaingan dalam mencari nasabah. Kualitas jasa yang disampaikan masih dirasa kurang oleh nasabah, daya tanggap karyawan terhadap pesoalan nasabah dirasa belum optimal, kecepatan dalam pemberian layanan kredit juga dirasa masih kurang. BPR KS berupaya untuk meningkatkan kualitas pelayanannya dengan peningkatan sumber daya manusia dan penggunaan teknologi yang semakin diperbaharui menjadi komitmen BPR KS kepada nasabah. Selain itu tingkat suku bunga juga menjadi hal yang sensitif bagi nasabah, tawaran bunga rendah menjadi daya tarik nasabah untuk mengunakan produk kredit sebuah bank. BPR masih dianggap memiliki BUnga yang tinggi dibandingkan dengan Bank Umum, Bank Syariah atau Pegadaian.

Citra yang selama ini dibagun dengan kinerja perusahaan dan promosi terus menerus memberikan dampak kepada masyarakat ketika nasabah ingin melakukan pinjaman kredit mikro. Citra perusahaan yang kuat akan memiliki nilai tambah dibanding bank lainnya. Masyarakat juga menganggap tingkat suku bunga yang diberikan BPR tergolong tinggi, hal tersebut menjadi salah satu pertimbangan nasabah dalam menentukan bank mana yang akan dipilih oleh nasabah.

Keputusan akan pengambilan produk mikro BPR KS dipengaruhi oleh beberapa faktor baik dari segi kualitas pelayanan yang diberikan, citra perusahaan dan tingkan suku bunga yang ditawarkan oleh BPR KS kepada masyarakat.

Berdasarkan latar belakang penelitian diatas, selanjudnya diidentifikasikan masalah penelitian yaitu apakah adanya pengaruh kualitas jasa yang diberikan, citra perusahaan dan 
tingkat suku bunga kredit terhadap keputusan pengambilan produk kredit mikro BPR KS di Bandung.

\section{Rumusan Masalah}

Berdasarkan uraian diatas, maka dapat diidentifikasikan masalahnya sebagai berikut:

1. Apakah terdapat Pengaruh Kualitas Jasa terhadap Keputusan Pengambilan Produk Kredit Mikro BPR KS Bandung?

2. Apakah terdapat Pengaruh Citra Perusahaan terhadap Keputusan Pengambilan Produk Kredit Mikro BPR KS Bandung?

3. Apakah terdapat Pengaruh Tingkat Suku Bunga terhadap Keputusan Pengambilan Produk Kredit Mikro BPR KS Bandung?

4. Apakah terdapat Pengaruh Kualitas Jasa, Citra Perusahaan dan Tingkat Suku Bunga Kredit terhadap Keputusan Pengambilan Produk Kredit Mikro BPR KS Bandung?

\section{Tujuan Penelitian}

Sesuai dengan persoalan yang diidentifikasikan, maka tujuan yang ingin dicapai dari penelitian ini yaitu :

1. Untuk mengetahui Pengaruh Kualitas Jasa terhadap Keputusan Pengambilan Produk Kredit Mikro BPR KS Bandung.

2. Untuk mengetahui Pengaruh Citra Perusahaan terhadap Keputusan Pengambilan Produk Kredit Mikro BPR KS Bandung.

3. Untuk mengetahui Pengaruh Tingkat Suku Bunga terhadap Keputusan Pengambilan Produk Kredit Mikro BPR KS Bandung.

4. Untuk mengetahui Pengaruh Kualitas Jasa, Citra Perusahaan dan Tingkat Suku Bunga Kredit terhadap Keputusan Pengambilan Produk Kredit Mikro BPR KS Bandung.

\section{Kegunaan Penelitian}

Dengan memperhatikan tujuan penelitian maka penulis mengharapkan dari penelitian ini dapat memberikan manfaat bagi penulis maupun pihak lain secara teoritis maupun praktis yaitu :

1. Kegunaan Akademis

a. Akademis, sebagai sumbangan bagi ilmu pengetahuan khususnya manajemen pemasaran melalui penerapan ilmu yang diperoleh dengan realita yang terjadi khususnya disektor perbankan.

b. Universitas, dimana hasil penelitian ini diharapkan menjadi sumber yang bermanfaat sebagai bahan dokumentasi serta menjadi sumber informasi ilmiah dan referensi bagi peneliti lain yang ingin melakukan penelitian serupa.

2. Kegunaan praktis

a. Masyarakat, sebagai alternatif solusi yang memperluas wawasan manajemen pemasaran dalam perencaaan strategis dalam mengembangkan lembaga keuangan seperti BPR, Koperasi dan Lembaga Keuangan lainnya.

b. Pihak BPR Karyajatnika Sadaya, tujuan penelitian ini dapat menambah gagasan pemikiran dan bahan masukan dalam pengambilan keputusan manajemen BPR KS Bandung dalam hal pengembangan serta peningkatan kualitas jasa yang diberikan, citra perusahaan yang telah dibangun dan tingkat suku bunga kredit yang ditawarkan.

\section{TINJAUAN PUSTAKA}

\section{Kajian Konsep Kualitas Jasa}

Kualitas jasa merupakan prasyarat bagi kelangsungan hidup dan perkembangan setiap perusahaan (Chinh \& Anh, 2008:28), karena meningkatkan kualitas jasa menjadi strategi penting mencapaikesuksesan dan bertahan didalam persaingan (Salam, Shawky \& Nahas, 2013:179). Beberapa defenisi kualitas jasa diambil dari beberapa literatur dan jurnal internasional. Defenisi kualitas jasa dijelaskan sebagai berikut.

Defenisi Kualitas menurut Kotler \& Keller (2012:G7) Kualitas jasa merupakan keseluruhan fitur dan karakteristik dari sebuah produk atau jasa yang mampu untuk memberikan kepuasan atau memenuhi keinginan.

Yousapronpaiboon \& Johnson (2013:176) kualitas jasa didefinisikan sebagai perbedaan antara persepsi pelanggan antara layanan yang ditawarkan oleh perusahaan dan harapan mereka tentang tawaran jasa dari perusahaan. Berbeda dengan Hasan, et al (2013:301)menjelaskan 
Kualitas pelayanan ditentukan oleh perbedaan antara penyedia layanan dan harapan pelanggan tentang kinerja dan evaluasi pelayanan yang diterima oleh pelanggan.

Beberapa peneliti menjelaskan pentingnya kualitas jasa dari hasil penelitian mereka seperti

a. Untuk bertahan dalam persaingan dan berkembang (Rahman, Haque \& Kan, 2012:115; Junaid - ul - haq, Abrar \& Nasir, 2013:245)

b. Meningkatkan niat beli konsumen (Hasan, et al, 2013:301; Rahman, Haque \& Kan, 2012:115; Junaid-ul-haq, Abrar \& Nasir, 2013:246)

c. Mempertahankan hubungan jangka panjang dengan konsumen (Junaid-ul-haq, Abrar \& Nasir,2013:245)

d. Meningkatkan kepuasan dan loyalitas (Mittal \& Gera, 2012:147; Liu \& Chen, 2013:158)

e. Mendapatkan pelanggan baru (Junaid - ul - haq, Abrar \& Nasir, 2013:246)

f. Bertahan dari persaingan harga (Chinh \& Anh, 2008:28)

g. Meningkatkan citra perusahaan (Ladhari, Ladhari \& Morales, 2010:224)

h. Merekomendasikan word-of-mouth(Lin \& Lu, 2010:22)

i. Meningkatkan keuntungan (Andronikidis, 2009:5; Salam, Shawky \& Nahas, 2013:179)

j. Menciptakan competitive advantage, differentiation dan excellence dipasar bisnis (Kumar, 2013:1; Andronikidis,2009:5; Putra, 2013:448)

Penelitian ini mendefenisikan kualitas jasa sebagai evaluasi pelayanan jasa bank yang diterima oleh pelanggan secara keseluruhan. Dimana defenisi kualitas jasa mencakup pada tangibles, reliability, responsiveness, assurance, dan empathy yang dijadikan sebagai ukuran untuk mengetahui kualitas jasa BPR KS Bandung.

\section{Kajian Konsep Citra Perusahaan}

Citra perusahaan telah menjadi strategi penting bagi banyak organisasi didalam peningkatan kinerja dan menjadi keunggulan bersaing, menurut Amini, et al (2012:192) menyatakan dengan memiliki citra perusahaan yang favorit dan ekuitas merek yang kuat dapat membangaun posisi strategi perusahaan dalam pasar

Defenisi citra perusahaan menurut Babić-Hodović, et al (2013:50) Citra perusahaan didefenisikan sebagai evaluasi keseluruhan pelanggan dari sebuah perusahaan berdasarkan reaksi terhadap produk perusahaan, layanan, kegiatan komunikasi, interaksi dengan perusahaan dan / atau perwakilan atau konstituen (seperti karyawan, manajemen, atau lainnya pelanggan) dan / atau kegiatan perusahaan yang dikenal sedangkan menurut Junaid - ul - haq, Abrar \&Nasir (2013:246) Citra perusahaan sebagai Intuisi dari perusahaan dalam pikiran pelanggan

Defenisi citra perusahaan yang digunakan dalam penelitian ini adalah citra perusahaan sebagai penilaian nasabah terhadap BPR KS yang diasosiasikan dalam bentuk kepercayaan yang dimiliki oleh bank, reputasi kinerja yang dikenal oleh masyarakat akan bank serta pengetahuan nasabah akan logo, simbol dan nama perusahaan.Dimensi Citra Perusahaan yang akan digunakan adalah Brand Personality, Organisational Assocation, Corporate Identity

\section{Kajian Konsep Harga atau Tingkat Suku Bunga}

Putra (2013:490) menjelaskan Total harga merupakan sejumlah biaya yang termasuk didalamnya harga, waktu, energi dan biaya fisik yang dikeluarkan untuk mengevaluasi, memilih, menggunakan atau memakai produk dari pasar yang spesifik dan Lovelock \& Wirtz (2011:622) Harga merupakan sesuatu yang dikeluarkan berupa uang, waktu dan usaha oleh konsumen untuk membeli atau memakai jasa.

Defenisi Suku Bunga menurut Kasmir (2005:152) bahwa Bunga bank dapat diartikan sebagai balas jasa yang diberikan bank yang berdasarkan prinsip konvensional kepada nasabah yang membeli atau menjual produknya. Hal yang senada juga menurut peneliti Nasab \& Roomi (2012:1084) Bunga bagi bank diartikan sebagai harga yang harus dibayar kepada nasabah (yang memiliki simpananya) dengan harga yang harus dibayar oleh nasabah kepada bank (nasabah yang memperoleh pinjaman) serta harga yang dibebankan kepada biaya-biaya jasa bank lainya.

Berdasarkan defenisi dari beberapa ahli, dapat diinterpetasikan bahwa suku bunga kredit adalahsuku bunga merupakan harga yang dibayar oleh nasabah atas dana pinjamanan yang diterima dari bank.Dalam pengukuran harga atau tingkat suku bunga dengan memodifikasi pada bagian indikator yang disesuaikan dengan konsep pada bank dengan menggunakan 3 item 
pertayaan yaitu : Tingkat suku bunga yang dibebankan kepada nasabah baru, Tingkat suku bunga yang dirasa wajar, Tingkat suku bunga bank lain

\section{Kajian Konsep Pengambilan Keputusan Konsumen}

Menurut Rahman, Haque \& Kan (2012:121) Niat beli konsumen berdasarkan pada penilaian konsumen yang direfleksikan setelah melakukan evaluasi untuk membeli sebuah produk atau jasa). sedangkan Lovelock \& Wirtz (2011:622) menjelaskan proses pembelian diartinya sebagai tingkatan dimana konsumen akan memilih, mengkonsumnsi dan mengevaluasi sebuah jasa dan Lin \& Lu (2010:2) berpendapat Niat beli disebut perilaku pertukaran tertentu yang dibuat setelah evaluasi konsumen terhadap suatu produk

Menurut Kotler \& Keller (2012:188) dalam pembelian konsumen melewati 5 tahap yaitu pengenalan masalah, pencarian informasi, evaluasi alternatif, keputusan pembelian, dan prilaku pasca pembelian.

Berdasarkan konsep keputusan pembelian yang telah dijelaskan maka Pengukuran keputusan pembelian dalam penelitian ini mengadopsi indikator (a) Pengenalan masalah : Seberapa penting kebutuhan kredit bagi nasabah, (b) Pencarian informasi : Sejauh mana pencarian informasi kredit dari bank-bank lain (c) evaluasi alternatif Sejauh mana keuntungan yang didapat jika memilih BPR KS (d) Keputusan pembelian :Keputusan untuk memakai BPR KS atau tidak.

\section{Kerangka Pemikiran}

Pengukuran kualitas jasa merupakan elemen penting untuk membedakan sejauh mana pelayanan BPR KS dengan pesaing lainya. Kualitas jasa yang unggul akan mampu memberikan kotribusi keuntungan perusahaan. Citra perusahaan telah menjadi strategi penting bagi banyak organisasi didalam peningkatan kinerja dimasa yang akan datang dan menjadi keunggulan bersaing. Citra perusahaan menjadi asset berharga sehingga perlu untuk dikelola oleh BPR KS dengan baik. Harga atau tingkat suku bunga ditetapkan tujuan utamanya adalah untuk memperoleh keuntungan. Namun demikian perusahaan harus berhati-hati agar suku bunga kredit yang ditawarkan tidak terlalu tinggi karena membuat nasabah tidak tertarik dan akan merugikan perusahaan. Persaingan yang semakin ketat membuat harga semakin sensitif.

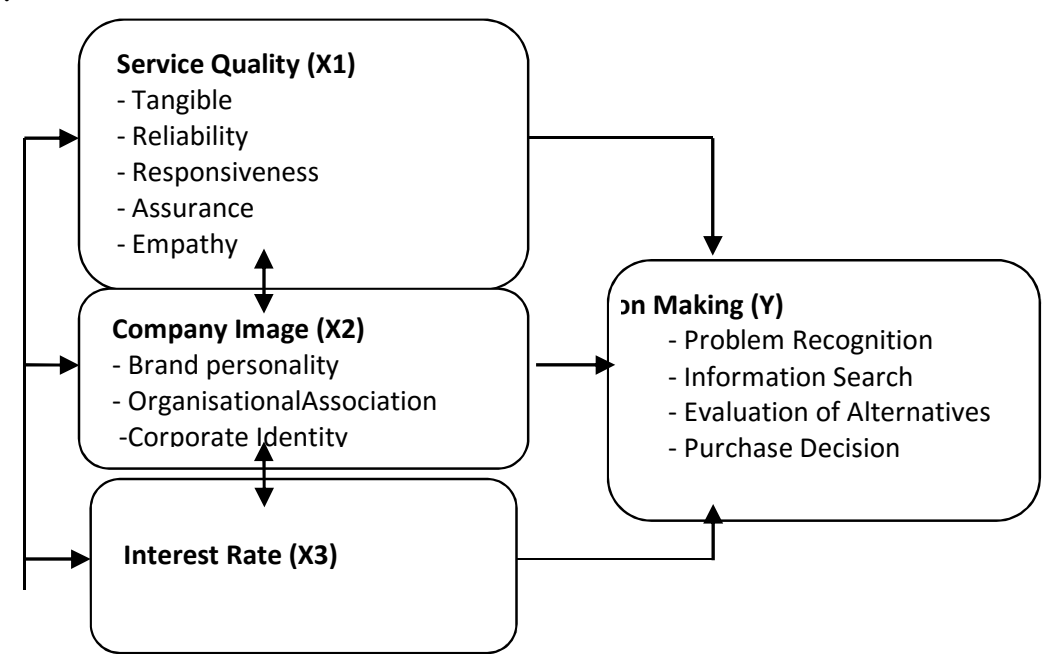

\section{Gambar 2 Paradigma Penelitian}

\section{Hipotesis}

Berdasarkan uraian kerangka pemikiran diatas maka dapat dirumuskan hipotesis penelitian secara umum yakni sebagai berikut :

1. Semakin tinggi Kualitas Jasa BPR KS maka semakin tinggi intensitas nasabah untuk memilih produk Mikro BPR KS Bandung.

2. Semakin baik Citra BPR KS maka semakin tinggi intensitas nasabah untuk memilih produk Mikro BPR KS Bandung. 
3. Semakin rendah Tingkat Suku Bunga BPR KS maka semakin tinggi intensitas untuk memilih produk Mikro BPR KS Bandung.

4. Terdapat Pengaruh antara Kualitas Jasa, Citra BPR, dan Tingkat Suku Bunga BPR KS terhadap Keputusan pengambilan Kredit Mikro BPR KS Bandung.

\section{METODE PENELITIAN}

Metode penelitian yang digunakan untuk mengetahui analisis pengaruh kualitas jasa, citra perusahaan dan tingkat suku bunga terhadap keputusan pengambilan kredit adalah metode deskriptif dan metode verifikatif. Penelitian deskriptif pada penelitian ini bertujuan untuk memperoleh gambaran mengenai kualitas jasa, citra perusahaan, tingkat suku bunga dan keputusan pengambilan kredit di BPR Karyajatnika Sadaya Bandung.Penelitian verifikatif bertujuan memahami variabel mana yang mempengaruhi dan variabel mana yang merupakan akibat serta menentukan sifat hubungan antara variabel independen dan pengaruh yang akan diperkirakan.

\section{Data}

Data primer diperoleh melalui pengumpulan data atau mendapatkan informasi langsung pada saat melakukan penelitian dilapangan melalui wawancara, observasi dan survei menggunakan instrument kuisioner. Sampe minimum yang digunakan sebanyak 110 orang dianggap sudah memenuhi syarat. Kuisioner disebar ke 110 nasabah mikro di delapan cabang unit Mikr BPR KS yang ada di Bandung

\section{Uji Validitas}

Menurut Sugiyono (2013:228) uji validitas dilakukan dengan menggunakan teknik korelasi product moment yang digunakan untuk menghitung korelasi antara masing-masing pertanyaan dengan skor total. Variabel kualitas jasa, citra perusahaan tingkat suku bunga dan keputusan pengambilan kredit diyatakan valid dimana nilai $r$ pearson lebih besar dari 0.3 sehingga item pertanyaan untuk setiap variabel diyatakan mampu untuk menjawab pertanyaan teoritis kualitas jasa, citra perusahaan tingkat suku bunga dan keputusan pengambilan kredit.

\section{Uji Reliabilitas}

Dialam penelitian ini menerapkan Coefficient alpha dimana Malhotra (2010:319). hasil uji nilai Cronbach Alpha Semua item reliabel, nilai kritis > 0.7Berdasarkan nilai koefisien reliabilitas tersebut maka item dimensi kualitas jasa, citra perusahaan, tingkat suku bunga dan keputusan pengambilan kredit dianggap andal atau menciptakan hasil yang konsisten jika pengukuran berulangkali dilakukan untuk mengukur hubungan antar variabel.

\section{Rancangan Analisis dan Uji Hipotesis Analisis Deskriptif}

Data hasil pengukuran variabel yang diperoleh adalah dengan nilai ordinal, agar dapat dianalisis secara statistik maka harus dinaikkan skalanya menjadi interval dengan menggunakan Method of Successive Interval (MSI) (Ridwan\&Kuncoro, 2011:30)

Tabel 2 Kategori Persentase Skor Jawaban Untuk Variabel Kualitas Jasa, Citra Perusahaan, Tingkat Suku Bunga dan Keputusan pengambilan

\begin{tabular}{|c|l|l|l|l|l|}
\hline $\begin{array}{c}\text { Rentang } \\
\text { Skor }\end{array}$ & Persentase & $\begin{array}{l}\text { Kategori } \\
\text { Kualitas Jasa } \\
(\mathbf{X 1})\end{array}$ & $\begin{array}{l}\text { Kategori Citra } \\
\text { Perusahaan } \\
(\mathbf{X 2})\end{array}$ & $\begin{array}{l}\text { Kategori } \\
\text { Tingakat } \\
\text { Suku Bunga } \\
(\mathbf{X 3 )}\end{array}$ & $\begin{array}{l}\text { Keputusan } \\
\text { pengambilan } \\
\text { kredit (Y1) }\end{array}$ \\
\hline $4.3-5,0$ & $80 \%-\leq 100 \%$ & $\begin{array}{l}\text { Sangat } \\
\text { Memuaskan }\end{array}$ & Sangat Baik & Sangat Tinggi & Sangat Setuju \\
\hline $3.5-4.2$ & $60 \%-<80 \%$ & Memuaskan & Baik & Tinggi & Setuju \\
\hline $2.7-3.4$ & $40 \%-<60 \%$ & $\begin{array}{l}\text { Cukup } \\
\text { Memuaskan }\end{array}$ & Cukup Baik & Cukup Tinggi & Cukup Setuju \\
\hline $1.9-2.6$ & $20 \%-<40 \%$ & $\begin{array}{l}\text { Kurang } \\
\text { Memuaskan }\end{array}$ & Kurang Baik & Rendah & Kurang Setuju \\
\hline $1.0-1.8$ & $10 \%-\_20 \%$ & $\begin{array}{l}\text { Tidak } \\
\text { memuaskan }\end{array}$ & Tidak Baik & $\begin{array}{l}\text { Sangat } \\
\text { Rendah }\end{array}$ & Tidak Setuju \\
\hline
\end{tabular}




\section{Analisis Verifikatif}

Analisis Data Verifikatif digunakan untuk menjawab hipotesis penelitian dengan cara mengkaji dan menghubungkan antara variabel penelitian. Analisis verifikatif dilakukan dengan menggunakan model persamaan struktural atau disebut dengan SEM (Structural Equation Model). 1. Pengembangan Model Berbasis Teori

2. Mengkontruksi Diagram Jalur untuk Hubungan Kausal

3. Mengkonversi Diangram Jalur Ke dalam Model Struktural dan Model Pengukuran

$\eta=\gamma_{1.1} \xi_{1}+\gamma_{1.2} \xi_{2}+\gamma_{1.3} \xi_{2}+\zeta_{1}$

4. Memilih Matriks Input dan Estimasi Model

5. Menilai Identifikasi Model Struktural

6. Evaluasi Kecocokan Model Berdasarkan Kriteria Goodness-of-fit

7. Interpretasi Model

\section{Uji Hipotesis}

\section{Secara parsial (Uji t)}

a. Hipotesis model pertama

$\mathrm{H}_{0}: \gamma_{1.1}=0 \quad$ Kualitas jasa tidak berpengaruh terhadap keputusan pengambilan produk kredit Mikro BPR KS Bandung.

Ha $: \gamma_{1.1} \neq 0 \quad$ Kualitas jasa berpengaruh terhadap keputusan pengambilan produk kredit Mikro BPR KS Bandung.

b. Hipotesis model kedua

$\mathrm{H}_{0}: \gamma_{1.2}=0 \quad$ Citra perusahaan tidak berpengaruh terhadap Keputusan pengambilan produk kredit Mikro BPR KS Bandung.

Ha $: \gamma_{1.2} \neq 0 \quad$ Citra perusahaan berpengaruh terhadap Keputusan pengambilan produk kredit Mikro BPR KS Bandung.

c. Hipotesis model ketiga

$\mathrm{H}_{0}: \gamma_{1.3}=0 \quad$ Suku bunga tidak berpengaruh terhadap Keputusan pengambilan produk kredit Mikro BPR KS Bandung.

Ha $: \gamma_{1.3} \neq 0 \quad$ Suku bunga berpengaruh terhadap Keputusan pengambilan produk kredit Mikro BPR KS Bandung.

Statistik uji yang digunakan adalah $: t=\frac{\hat{\gamma}_{11}}{\operatorname{se}\left(\hat{\gamma}_{11}\right)}$

\section{Secara Simultan (Uji F)}

a. Hipotesis model ke empat

$\mathrm{H}_{0}$ : Semua $\beta_{\mathrm{i}}=0 \quad$ Kualitas jasa, citra perusahaan dan suku bunga secara simultan tidak $\mathrm{i}=1,2,3$ berpengaruh terhadap keputusan pengambilan produk kredit Mikro BPR KS Bandung.

Ha : Ada $\beta_{\mathrm{I}} \neq 0$

Kualitas jasa, citra perusahaan dan suku bunga secara simultan $\mathrm{i}=1,2,3$ berpengaruh terhadap keputusan pengambilan produk kredit Mikro BPR KS Bandung.

\section{HASIL DAN PEMBAHASAN Profil Responden}

Dari data kuesioner didapat karakteristik nasabah BPPR KS berjenis kelamin Pria sebanyak $69,1 \%$. Responden yang yang berjenis kelamin Wanita hanya ada 34 orang atau 30,9\%. usia kurang dari 25 tahun (15.55), usia 25-35 tahun (41.8\%), usia 36-45 tahun (31.8\%),dan usia diatas 45 tahun (10.9\%) dari data diatas dilihat bahwa usia rata-rata didominasi oleh usia 25-35 tahun, sedangkan untuk profil pendidikan SD (7.3\%), SMP (16.4\%), SMA (47.3\%), D1/D3 
(15.5\%) dan S1 (12.7\%). Untuk Penghasilan perbulan maka dapat dilihat untuk nasabah yang berpenghasilan 2-4 juta (37.3\%), 4-6juta (30.9\%), 6-8 juta (20.9\%) dan diatas 8 juta (10.9\%).Dari hasil pengumpulan data kuisioner, dilakukan direkapitulasi data dari setiap indikator variabel, Setiap variabel yang diteliti akan dijabarkan dalam analisis deskriptif dengan menggunakan garis kontinu yang telah dijelaskan pada tabel 4 berikut :

Table 3 Analisis Deskriptif

\begin{tabular}{|c|c|c|c|c|}
\hline Variabel & $\begin{array}{c}\text { Total } \\
\text { Skor }\end{array}$ & Persentase Skor & Mean Skor & Kategori \\
\hline Kualitas jasa & 399.00 & $72.54 \%$ & 3.626 & Baik \\
\hline Citra Perusahaan & 395.33 & $71.87 \%$ & 3,59 & Baik \\
\hline Tingkat Suku Bunga & 277.33 & $50.73 \%$ & 2.52 & Cukup \\
\hline $\begin{array}{c}\text { Keputusan Pengambilan } \\
\text { Kredit }\end{array}$ & 379.75 & $69.04 \%$ & 3.45 & Positif \\
\hline
\end{tabular}

\section{Analisis Verifikatif}

Uji Normalitas Data, Pada uji normalitas multivariat, diperoleh nilai chi-square sebesar 51,67 dengan p-value sebesar 0,000, oleh karena p-value lebih kecil dari 0,05 dapat dijelaskan bahwa data variabel manifes (indikator) tidak berdistribusi normal multivariat.Karena hasil uji normalitas menunjukkan bahwa data tidak berdistribusi normal multivariat, maka seperti yang dikemukakan Raykov \& Marcoulides (2006; 30) bila data tidak berdistribusi normal, metode estimasi yang digunakan adalah Robust maximum likelihood (RML)

Hasil Uji Kecocokoan Model, BerdasarkanUji goodness of fit seperti yang dijelaskanoleh Hair et al 2010 dalamLatan (2013:49) bahwapenggunaankriteria goodness of fit dianggapsudahmencukupiuntukmenilaikelayakansuatu model, dimana Goodness of fit untukkriteria (1) Absolute fit Indices (Root Mean Square Error of Approximation RMSEA 0.075 memenuhikriteriabaik), (2) untuk Incremental fit Indices (Normed fit Index NFI 0.924 memenuhikriteriabaik, Comparative Fit Index CFI 0.969 memenuhi kriteria baik, Incremental fit Indices IFI 0.970 memenuhikriteriabaikdan Relative Fit Indices RFI 0.905 memenuhikriteriabaik).

Gambar 2 Model Pengukuran

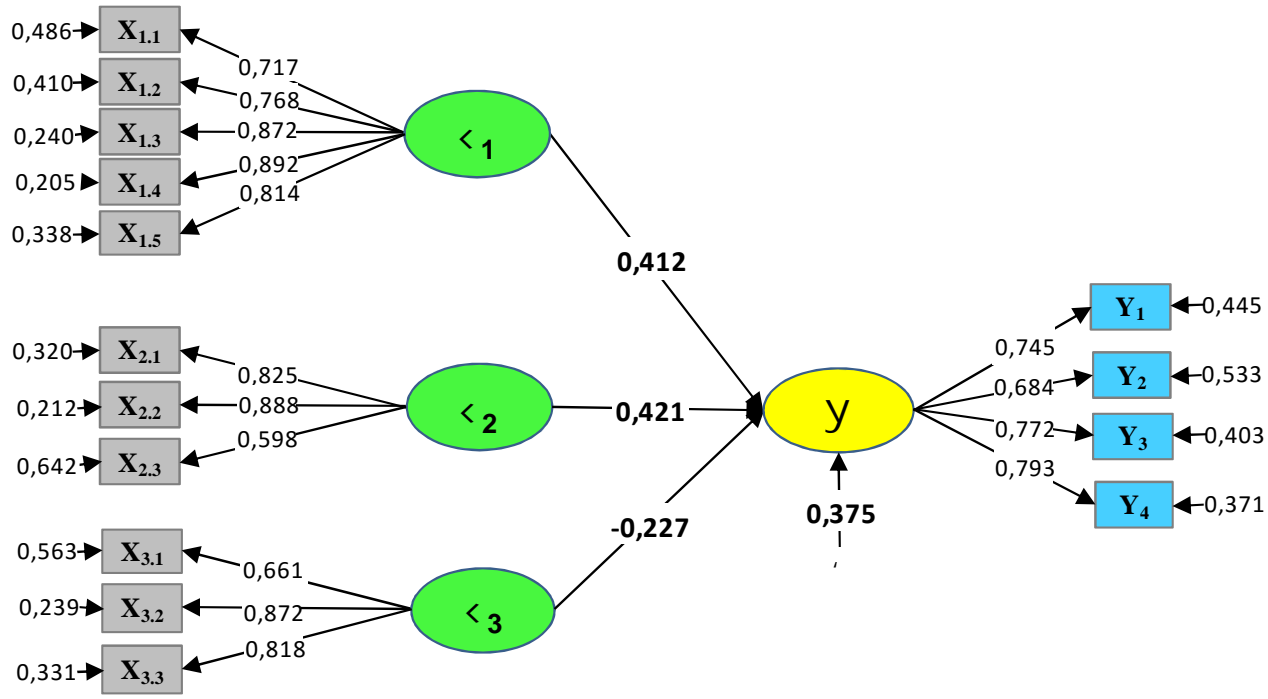


Tabel 4 Ringkasan Hasil Uji Parameter Model Pengukuran Variabel

\begin{tabular}{|c|c|c|c|c|c|c|c|c|}
\hline Variabel & $\begin{array}{l}\text { Dimen } \\
\text { si }\end{array}$ & $\begin{array}{l}\text { Bobot } \\
\text { Fakto } \\
\text { r }\end{array}$ & $\begin{array}{c}\mathrm{t} \\
\text { hitung }\end{array}$ & $\begin{array}{c}\mathrm{t} \\
\text { tabe } \\
1\end{array}$ & $\begin{array}{c}\text { Keteranga } \\
n\end{array}$ & $\begin{array}{c}\text { Koefisie } \\
\mathrm{n} \\
\text { Korelasi } \\
\left(\mathrm{R}^{2)}\right.\end{array}$ & $\begin{array}{c}\text { Composi } \\
\text { te } \\
\text { Reliabilit } \\
\text { y (CR) }\end{array}$ & $\begin{array}{c}\text { Averag } \\
\text { e } \\
\text { Varian } \\
\text { ce } \\
\text { Extract } \\
\text { ed } \\
\text { (AVE) }\end{array}$ \\
\hline \multirow{2}{*}{ KualitasJasa } & $\mathrm{X}_{1.4}$ & 0,892 & 33.89 & $\begin{array}{c}1,9 \\
6\end{array}$ & signifikan & 0,795 & \multirow{2}{*}{0,908} & \multirow{2}{*}{0,665} \\
\hline & $\mathrm{X}_{1.3}$ & 0,872 & 30.06 & $\begin{array}{c}1,9 \\
6\end{array}$ & signifikan & 0,760 & & \\
\hline Citra Perusahaan & $\mathrm{X}_{2.2}$ & 0,888 & 20.99 & $\begin{array}{c}1,9 \\
6\end{array}$ & Signifikan & 0,788 & 0,820 & 0,609 \\
\hline $\begin{array}{l}\text { Tingkat } \\
\text { SukuBunga }\end{array}$ & $\mathrm{X}_{3.2}$ & 0,872 & 17.86 & $\begin{array}{c}1,9 \\
6\end{array}$ & Signifikan & 0,761 & 0,830 & 0,622 \\
\hline $\begin{array}{l}\text { KeputusanPenga } \\
\text { mbilan Kredit }\end{array}$ & $\mathrm{Y}_{4}$ & 0,793 & 11.85 & $\begin{array}{c}1,9 \\
6\end{array}$ & signifikan & 0,629 & 0,838 & 0,562 \\
\hline
\end{tabular}

Berdasarkan hasil confirmatory factor analysis dapat dilihat nilai bobot faktor setiap dimensi lebih besar dari 0,40. Nilai composite reliability (CR) sebesar 0,908 untuk kualitas jasa, 0.820 untuk citra perusahaan, 0.830 untuk tingkat suku bunga, dan 0.838 untuk keputusan penambilan kredit atau secara keseluruhan lebih besar dari 0,70 menunjukkan bahwa semua indikator memiliki kekonsistenan dalam mengukur kualitas jasa, citra, tingkat suku bunga dan pengambilan keputusan kredit. Selanjutnya nilaia verage variance extracted (AVE) informasi yang terdapat pada masing-masing dimensi dapat tercermin melalui variabel laten setiap variabel.

Tabel 5 Rangkuman Hasil Uji Statistik

\begin{tabular}{|c|c|c|c|c|}
\hline Jalur & $\mathrm{t}_{\text {tabel }}$ & $\mathrm{t}_{\text {hitung }}{ }^{*}$ & Keterangan & $\begin{array}{c}\text { Koefisien } \\
\text { Korelasi (R- } \\
\text { Square) }\end{array}$ \\
\cline { 1 - 3 }$\xi_{1} \rightarrow \eta$ & 0,412 & 4,446 & signifikan & \multirow{2}{*}{0,625} \\
\cline { 1 - 3 }$\xi_{2} \rightarrow \eta$ & 0,421 & 4,613 & signifikan & \\
\cline { 1 - 3 }$\xi_{3} \rightarrow \eta$ & $-0,227$ & $-2,641$ & Signifikan & \\
\hline
\end{tabular}

Persamaan struktural pengaruh kualitas jasa, citra perusahaan dan suku bunga terhadap Keputusan pengambilan produk kredit diformulasikan sebagai berikut:

$$
\begin{aligned}
& \eta=\gamma_{1.1} \xi_{1}+\gamma_{1.2} \xi_{2}+\gamma_{1.3} \xi_{2}+\zeta_{1} \\
& \eta=0.412 * \xi_{1}+0.421 * \xi_{2}-0.227 * \xi_{3} \text {, Errorvar. }=0.375, R^{2}=0.625 \\
& \begin{array}{lll}
(0.0926) & (0.0912)(0.0858) & (0.0884)
\end{array} \\
& \begin{array}{llll}
4.446 & 4.613 & -2.641 \quad 4.241
\end{array}
\end{aligned}
$$

Dari hasil pengolahan data seperti yang di rangkum dalam tabel 5 maka Kualitas jasa, citra perusahaan dan suku bungasecara bersama-sama memberikan pengaruh sebesar 62,5\% terhadap keputusan pengambilan produk kredit Mikro BPR KS Bandung, sedangkan sisanya sebesar 37,5\% merupakan pengaruh faktor-faktor lain yang tidak diteliti 
Tabel 6 Pengaruh variabel X1, X2 dan X3 Secara Parsial Terhadap Y

\begin{tabular}{|c|c|c|c|c|c|}
\hline Hypothesis & $\begin{array}{c}\text { Koefisien } \\
\text { Jalur }\end{array}$ & $\mathbf{t}_{\text {hitung }}$ & $\mathbf{T}_{\text {tabel }}$ & Keputusan & Kesimpulan \\
\hline $\begin{array}{l}\text { Ho: } \rho \mathrm{yx}_{1}=0 \\
\text { Ha: } \rho \mathrm{yx}_{1} \neq 0\end{array}$ & 0,412 & 4,446 & 1,96 & $\begin{array}{c}\text { Ho Ditolak } \\
\text { dan Ha } \\
\text { Diterima }\end{array}$ & Signifikan \\
\hline $\begin{array}{l}\text { Ho: } \rho \mathrm{yx}_{2}=0 \\
\text { Ha: } \rho \mathrm{yx}_{2} \neq 0\end{array}$ & 0,421 & 4,613 & 1,96 & $\begin{array}{c}\text { Ho Ditolak } \\
\text { dan Ha } \\
\text { Diterima }\end{array}$ & Signifikan \\
\hline $\begin{array}{l}\text { Ho: } \rho \mathrm{yx}_{3}=0 \\
\text { Ha: } \rho \mathrm{yx}_{3} \neq 0\end{array}$ & $-0,227$ & $-2,641$ & 1,96 & $\begin{array}{c}\text { Ho Ditolak } \\
\text { dan Ha } \\
\text { Diterima }\end{array}$ & Signifikan \\
\hline
\end{tabular}

Berdasarkan hasil pengujian dapat dilihat nilai $t_{\text {hitungvariabel lebih besar dari } t_{\text {tabel }}(1,96)}$ Karena nilai $t_{\text {hitung }}$ lebih besar dibanding $t_{\text {tabel }}$, maka dengan tingkat kekeliruan $5 \%$ diputuskan untuk menolak Ho sehingga Ha diterima.

Tabel 7 Pengaruh Antar Variabel Laten

\begin{tabular}{|c|c|c|c|c|}
\hline \multirow{2}{*}{ Variabel } & \multirow{2}{*}{$\begin{array}{c}\text { Koefisie } \\
\text { n Jalur }\end{array}$} & \multicolumn{2}{|c|}{ Pengaruh } & \multirow{2}{*}{$\begin{array}{c}\text { Pengaru } \\
\text { h Total }\end{array}$} \\
& & Langsung & $\begin{array}{c}\text { Tidak } \\
\text { Langsung }\end{array}$ & \\
\hline Kualitas Jasa (X1) & 0.412 & $\mathbf{1 7 . 0 \%}$ & & \\
\hline Citra Perusahaan (X2) & 0.421 & $\mathbf{1 7 . 7 \%}$ & & \\
\hline $\begin{array}{l}\text { Tingkat Suku Bunga } \\
\text { (X3) }\end{array}$ & -0.227 & $\mathbf{5 . 2 \%}$ & & \\
\hline X1 dan X2 Terhadap Y & 0.495 & & $\mathbf{2 4 . 3 \%}$ & \\
\hline X1 dan X3 terhadap Y & 0.427 & & $\mathbf{1 8 . 1 \%}$ & \\
\hline X2 dan X3 terhadap Y & 0.452 & & $\mathbf{2 0 . 1 \%}$ & \\
\hline X1, X2, X3 terhadap Y & & & & $\mathbf{6 2 . 5 \%}$ \\
\hline $\begin{array}{l}\text { Pengaruh Variabel lain } \\
\text { Terhadap Y ( ) }\end{array}$ & & & & $\mathbf{3 7 . 5 \%}$ \\
\hline
\end{tabular}

a. Besarnya kontribusi kualitas jasa terhadap keputusan pengambilan kredit sebesar $17.0 \%$. Oleh karena itu untuk mengoptimalkan jumlah kredit yang diambil oleh nasabah maka kualitas jasa harus dioptimalkan. Temuan penelitian ini diperkuat dengan peryataan Junaid-ul-haq, Abrar \& Nasir (2013:246) dimana kualitas jasa akan mendorong pelanggan untuk lebih banyak membeli dan mempergunakan jasa. Temuan penelitian ini juga didukung oleh pendapat Chinh \& Anh (2008:28)menjelaskan bahwa kualitas jasa adalah kunci untuk profitabilitas jangka panjang karena mempengaruhi niat pembelian kembali.Hal ini sejalan dengan hasil penelitian yang dilakukan oleh Rahman, Haque \& Kan (2012) dimana kualitas jasa memiliki pengaruh positif yang signifikan didalam pengambilan keputusan konsumen dalam memilih provider internet di Malaysia.Penelitian yang dilakukan Oktarina (2011) pada bank mandiri menunjukkan adanya pengaruh nilai jasa yang dirasakan kepada nasabah sebesar 0.18 (atau 18\%) dan sistem penyampaian jasa yang diberikan oleh bank mandiri cabang pondok kelapa mempengaruhi keputusan nasabah dalam menggunakan jasa bank mandiri sebesar 0.33 (atau 33\%) dimana dijelaskan adanya pengaruh positif antara kualitas jasa dengan keputusan penggunaan jasa bank mandiri.

b. Besarnya kontribusi citra perusahaan terhadap keputusan pengambilan kredit sebesar $17.7 \%$. Oleh karena itu untuk mengoptimalkan jumlah kredit yang diambil oleh nasabah maka citra perusahaan harus dioptimalkan. Hal ini sejalan dengan hasil penelitian yang dilakukan oleh 
Chattananon, et al (2008) bahwa program brand yang dikembangkan memiliki dampak positif terhadap pembelian pelanggan. Lin \& Lu (2010) didalam hasil penelitiannya menjelaskan adanya pengaruh yang signifikan positif citra perusahaan terhap niat beli konsumen.Penelitian yang dilakukan oleh Oktarina (2011) menunjukkan bahwa citra merek yang dimiliki Bank Mandiri mempengaruhi keputusan nasabah dalam menggunakan jasa Bank Mandiri secara tidak langsung melalui nilai jasa sebesar 0.276 atau $(27,6 \%)$ dari penelitian Oktarina (2011) disimpulkan adanya pengaruh signifikan dan positif antara citra merek mandiri terhadap keputusan menggunakan jasa bank mandiri.

c. Besarnya kontribusi Tingkat Suku Bunga terhadap keputusan pengambilan kredit sebesar 5.2\%. Oleh karena itu untuk mengoptimalkan jumlah kredit yang diambil oleh nasabah maka Tingkat Suku Bunga harus diperhatikan dan tindak terlalu tinggi. Hasil uji hipotesis menjelaskan bahwa semakin tingginya bunga yang ditawarkan maka semakin berkurang nasabah untuk mengambil kredit di BPR KS.Hasil penelitian ini didukung oleh pendapat Lovelock \& Wirtz (2011:67) bahwa harga seringkali menjadi faktor kunci didalam keputusan pembelian

d.Besarnya kontribusi Tingkat Suku Bunga terhadap keputusan pengambilan kredit sebesar 5.2\%. Oleh karena itu untuk mengoptimalkan jumlah kredit yang diambil oleh nasabah maka Tingkat Suku Bunga harus diperhatikan dan tindak terlalu tinggi. Hasil uji hipotesis menjelaskan bahwa semakin tingginya bunga yang ditawarkan maka semakin berkurang nasabah untuk mengambil kredit di BPR KS.Hasil penelitian ini didukung oleh pendapat Lovelock \& Wirtz (2011:67) bahwa harga seringkali menjadi faktor kunci didalam keputusan pembelian

\section{PENUTUP KESIMPULAN}

1. Hasil penelitian menggambarkan bahwa BPR KS telah memberikan pelayanan yang Baik kepada nasabah secara keseluruhan (total skor 72.54\%). Pengukuran variabel laten kualitas jasa pada variabel laten kualitas jasa, dimensi X1.4 (assurance) dan X1.3 (responsiveness) memiliki bobot faktor paling besar yang menunjukkan bahwa assurance dan responsiveness paling penting dalam mencerminkan variabel laten kualitas jasa. Kualitas jasa berpengaruh positif dan signifikan terhadap keputusan pengambilan produk kredit. Besarnya kontribusi kualitas jasa yang secara langsung terhadap keputusan pengambilan kredit adalah 17\%. Berdasarkan hasil penelitian ini dapat disimpulkan semakin baik kualitas jasa maka semakin meningkatkan pengambilan kredit mikro di BPR KS Bandung.

2. Citra BPR KS dinilai sudah baik dimenurut nasabah (total skor 71.87\%), Variabel laten organisational assocation menjadi faktor yang paling berpengaruh dalam pembentukan Citra BPRKS. Citra perusahaan berpengaruh positif dan signifikan terhadap keputusan pengambilan produk kredit. Besarnya kontribusi citra perusahaan yang secara langsung terhadap keputusan pengambilan kredit adalah $17.7 \%$. Berdasarkan hasil penelitian ini dapat disimpulkan bahwa semakin baik Citra Perusahaan maka semakin meningkatkan pengambilan kredit mikro di BPKS Bandung.

3. Tingkat suku bunga yang ditawarkan BPR KS dianggap cukup atau wajar oleh nasabah. (total skor 50.73\%). Hasil pengukuran variabel laten suku bunga, indikator X3.2 (tingkat suku bunga yang diinginkan) memiliki bobot faktor paling besar yang menunjukkan bahwa indikator tingkat suku bunga yang diinginkan paling penting yang harus diperhatikan. Tingkat suku bunga berpengaruh negatif terhadap Keputusan pengambilan produk kredit. Besarnya kontribusi tingkat suku bunga yang secara langsung terhadap keputusan pengambilan kredit adalah $5.2 \%$. Berdasarkan hasil penelitian ini dapat disimpulkan semakin rendah suku bunga yang ditawarkan akan meningkatkan keputusan pengambilan kredit mikro BPR KS dan sebaliknya semakin tinggi tingkat suku bunga kredit maka keputusan untuk mengambil kredit semakin menurun. 
4. Kualitas Jasa, Citra Perusahaan dan Tingkat Suku bunga secara simultan berpengaruh positif dan signifikan terhadap Keputusan pengambilan produk kredit. Kualitas jasa, Kualitas Jasa, Citra Perusahaan, Tingkat Suku bunga memiliki pengaruh sebesar 62,5\% terhadap keputusan pengambilan kredit. Terdapat $37,5 \%$ pengaruh terhadap keputusan pengambilan kredit yang dijelaskan oleh variabel lain diluar dari kualitas jasa, citra perusahaan dan Tingkat suku bunga. Variabel lain tersebut diduga customer relationship management.

\section{SARAN}

1. Pihak Manajemen atau pengambil keputusan di BPR KS perlu melakukan perbaikan terhadap beberapa aspek untuk meningkatkan pertumbuhan kredit. Pertama memperhatikan kualitas jasa sebagai salah satu faktor keunggulan bersaing. Dengan melihat faktor-faktor yang lebih dominan yang mempengaruhi pengambilan kredit diharapkan unsur tersebut lebih diperhatikan dan dikelola dengan baik. Adanya jaminan kualitas jasa yang ditawarkan dengan menciptakan sumber daya manusia lebih ramah, sopan, peduli dan mampu berkomunikasi yang baik dengan nasabah serta meningkatkan kompetensi staf dalam memberikan jasa perbankan. Hal tersebut dapat ditingkatkan dengan pelatihan dan pengembangan terutama untuk para staf frontliner. Evaluasi kualitas jasa ini dapat digunakan untuk memperbaiki terus menerus kualitas layanan di BPR KS. Kedua meningkatkan citra, yaitu keyakinan dan kepercayaan dibenak nasabah. BPR KS harus mampu untuk mengkomunikasikan nilai-nilai tersebut kepada masyarakat sehingga pengalaman, perasaan dan ide yang diingat oleh nasabah akan ditrasformasikan ke arti yang positif yang akan menjadi media promosi BPR KS yang efektif kepada masyarakat. Membangun citra positif dengan mengkomunikasikan kepada masyarakat bahwa produk kredit mikro BPR KS lebih unggul dibanding dengan bank lain, proses yang cepat dan persyaratan yang mudah dan membangun kepercayaan masyarakat atas reputasi BPR KS sebagai BPR terbesar dan terpercaya. Ketiga tingkat suku bunga, dengan mengetahui tingkat suku bunga pesaing dan memperhatikan perubahan tingkat suku bunga lingkungan baik dari Bank Umum, BPR atau Leasing. Hal ini dikarenakan nasabah memiliki pengetahuan yang cukup akan tingkat suku bunga dan tingkat suku bunga merupakan hal sensitif bagi sebagian nasabah, oleh sebab itu perlunya pemahaman karakteristik nasabah serta komunikasi yang jelas agar nasabah mudah memahami suku bunga yang ditawarkan.

2. Peneliti berikutnya perlu mengembangkan penelitian terhadap lembaga keuangan mikro dimasa yang mendatang, mengingat masih minimnya penelitian terhadap BPR dibandingkan dengan Bank Umum. Penelitian dengan variabel yang sama terhadap masyarakat yang memiliki lingkungan budaya, sosial dan ekonomi yang berbeda mungkin akan mempengaruhi persepsi nasabah akan kualitas jasa. Penelitian sebaiknya tidak terbatas pada kualitas jasa, citra dan tingkat suku bunga, namun juga pada customer relationship management yang dapat mempengaruhi keputusan pengambilan produk kredit.

\section{REFERENSI}

Andronikidis, Andreas. 2009. Linking Dimensions of Perceived Service Quality to Actual Purchase Behavior. Vol. 4 No. 1, pp. 4-20. DOI10.1108/14502190910956666 www.emeraldinsight.com/1450-2194.htm.

Amini, Alireza., Mahdi Darani., Minoo Afshani., and Zahra Amini. 2012. Effectiveness of Marketing Strategies and Corporate Image on Brand Equity as a Sustainable Competitive Advantage. Interdisciplinary Journal Of Contemporary Research In Business. Vol. 4 No. 2, pp 192-205. ijcrb.webs.com.

Babić, Vesna Hodović., Maja Arslanagić., and Eldin Mehić. 2013. Importance of Internal Marketing for Service Companies Corporate Reputation and Customer Satisfaction. Journal of Business Administration Research. Vol. 2 No. 1, pp 49-57. www.sciedu.ca/jbar.

Bank Indonesia, 1998. Undang-Undang Republik Indonesia Nomor 7 Tahun 1992 Tentang Perbankan sebagaimana telah diubah dengan Undang-Undang Nomor 10 Tahun 1998. Jakarta: Bank Indonesia. 
Bank Indonesia, 2012. Peraturan Bank Indonesia Nomor 14/14/PBI/2012 tentang Tentang Pemberian kredit atau pembiayaan oleh Bank Umum dan Bantuan Teknis dalam Rangka Pengembangan Usaha Mikro, Kecil, dan Menegah. Jakarta : Bank Indonesia.

Bank Indonesia, 2012. Peraturan Bank Indonesia No.14/14/PBI/2012 tanggal 18 Oktober 2012 tentang Transparansi dan Publikasi Laporan Bank. Jakarta : Bank Indonesia.

Basuki, Eko Yanto. 1995. Hubungan Perhitungan Bianya Dana dengan Suku Bunga Pinjaman Kartu kredit Bank X. Bandung : Unpad Bandung.

Bravo, Rafael. and Jose M Pina. 2011. Communicating Spanish banks' identities: the role of websites. Online Information Review. Vol. 36 No. 5, pp. 675-697. www.emeraldinsight.com/1468-4527.htm.

Bravo, Rafael., Teresa Montaner., and Jose M Pina. 2012. Corporate brand image of financial institutions: a consumer approach. Journal of Product and Brand Management. Vol. 21 No. 4, pp 232-245. www.emeraldinsight.com/1061-0421.htm

Blomback, Anna. and Marcela Ramı'rez-Pasillas. 2012. Exploring the logics of corporate brand identity formation.Corporate Communications: An International Journal. Vol. 17 No. 1, pp 7-28. www.emeraldinsight.com/1356-3289.htm.

Barker. Chris, Nancy Pistrang \& Robert Elliot. 2002. Research Methods in Clinical Psychology. Second edition. John Wiley \& Sons, LTD Chichester England.

BPS. 2013. Jawa Barat Dalam Angka. Bandung : Badan Pusat Statistik Jawa Barat.

Chattananon, Apisit., Meredith Lawley., Numchai Supparerkchaisakul., and Lackana Leelayouthayothin. 2008. Impacts of a Thai cause-related marketing program on corporate image. International Journal of Emerging Markets. Vol. 3 No. 4, pp. 348-363 www.emeraldinsight.com/1746-8809.htm.

Chattananon, Apisit., Meredith Lawley., Jirasek Trimetsoontorn., Numchai Supparerkchaisakul., and Lackana Leelayouthayothin. 2007. Building corporate image through societal marketing programs. Society and Business Review. Vol. 2 No. 3, pp. 230-253. www.emeraldinsight.com/1746-5680.htm.

Chinh, Vu Thi My. and Nguyen Viet Anh. 2008. Measuring Customer Satisfaction Base On Service Quality Gap At A Lokal Bank In Vietnam. Journal of International Business Research. Vol. 7 Special Issue. 3, pp. 27-50.

Coker, Anthonia., Jeremiah Iyamabo., and Olutayo Otubanjo. 2013. Investigating Service Responsiveness in Customer Perception of the Corporate Logo. International Journal of Business and Management. Vol. 8 No. 11, pp 38-50. http://dx.doi.org/10.5539/ijbm.v8n11p38.

Fitzsimmons, James A. and Mona J Fitzsimmons. 2011. Service Management : Operation, Strategy, Information Technology. Seventh Edition. New York : McGraw Hill.

Flavian, Carlos., Miguel Guinaliu., and Eduardo Torres. 2005. The Influence of Corporate Image On Consumer Trust : A Comparative Analysis in Traditional Versus Internet Banking. Vol. 15 No.4, pp 447-470. www.emeraldinsight.com/1066-2243.htm.

Hasan, Ameer., Usman Asif., Muhammad Irfan Arif., and Nimra Khan. 2013. ATM Service Quality and its Effect on Customer Retention: A Case from Pakistani Banks. Information Management and Business Review. Vol. 5 No. 6, pp. 300-305 (ISSN 2220-3796).

Hasanudin, Mohamad dan Prihatiningsih. 2010. Analisis Pengaruh Dana Pihak ketiga, Tingkat Suku Bunga Kredit, Non Performance Loan (NPL), dan Tingkat Inflasi Terhadap Penyaluran Kredit Bank Perkreditan Rakyat (BPR) di Jawa Tengah. Semarang: Politeknik Negeri Semarang.Vol.5. No.1 p25-31.

Hair.Jr., JF., Anderson, R.E. Tatham, R.L., and Black, W.C., 2006. Multivariate Data Analysis. Fith Edition. Prince-Hall. Inc., New Jersy.

Herstein, Ram.,Yoram Mitki., and Eugene D. Jaffe. 2008. Corporate Image Reinforcement in an Era of Terrorism through Integrated Marketing Communication. Vol. 11 No. 4, pp 360 370. www.palgrave-journals.com/crr/.

Hosseini, Seyed Yaghoub., Manijeh Bahreini Zadeh., and Alireza Ziaei Bideh. 2013. Providing a Multidimensional Measurement Model for Assessing Mobile Telecommunication Service Quality (MS-Qual). Iranian Journal of Management Studies (IJMS). Vol. 6 No. 2, pp. $7-$ 29. 
Joseph F. Hair, Jr., William C. Black, Barry J.Babin, Rolph E. Anderson, Ronald L.Tatham, 2006.Multivariate Data Analysis. (sixth edition), Pearson Prentice Hall Education International.

Junaid-ul-haq, Muhammad Abrar. and Rao Umer Nasir. 2013. How Customer Loyalty Model Be Operative? A study of Cellular Phone Service Providers in Pakistan. Information Management and Business Review. Vol. 5 No. 5, pp. 245-256.ISSN 2220-3796

Kasmir. 2005. Pemasaran Bank. Jakarta : Kencana.

Kumar, Anil. 2013. Constructing a Measurement in Service Quality for Indian Banks: Structural Equation Modeling Approach. Journal of Internet Banking and Commerce. Vol. 18 No.1, pp 1-13 (http://www.arraydev.com/commerce/jibc/).

Kotler, Philip. and Kevin Lane Keller. 2012. Marketing Management. Fourteenth Edition. England: Printice Hall. page 188,198,332,396,405,408.

Ladhari, Riadh., Ines Ladhari., and Miguel Morales. 2010. Bank Service Quality : Comparing Canadian and Tunisian Customer Perceptions. International Journal of Bank Marketing. Vol. 29 No. 3, pp. 224-246. DOI 10.1108/02652321111117502 www.emeraldinsight.com/0265-2323.htm.

Leblanc, Gaston. and Nha Nguyen. 1996. Cues used by customers evaluating corporate image in service firms: an empirical study in financial institutions. The International Journal of Service Industry Management. Vol. 7 No. 2, pp 30-38.

Liu, Xilong. and Yizeng Chen. 2013. A FAHP-FUZZY Approach of Evaluating Banking Service Quality. International Journal of Business and Management. Vol. 8 No. 14, pp. 158-167. www.ccsenet.org/ijbm.

Lin, Long-Yi. and Ching-Yuh Lu. 2010. The influence of corporate image, relationship marketing, and trust on purchase intention: the moderating effects of word-of-mouth. Tourism Review. Vol. 65 No. 3, pp. 16-34. DOI 10.1108/16605371011083503.

Lovelock, Christopher. and Jochen Wirtz. 2011. Services Marketing, Strategy : People, Technology, Strategy. New Jersey : Prentice Hall. page 59,67,158,164,406,620,622.

Malik, Muhammad Ehsan., Muhammad Mudasar Ghafoor., and Hafiz Kashif Iqbal. 2012. Impact of Brand Image, Service Quality and price on customer satisfaction in Pakistan Telecommunication sector. International Journal of Business and Social Science. Vol. 3 No. 23, pp 123-129. www.ijbssnet.com.

Marković, Suzana., Sanja Raspor., Gordana Ivankovič., and Tanja Planinc. 2013. A study of expected and perceived service quality in Croatian and Slovenian hotel industry. European Journal of Tourism Research. Vol. 6 No. 1, pp 36-52.

Malhotra, Naresh K. 2010. Marketing Research : An Applied Orientation. Sixth Edition. New Jersey : Printice Hall.

Mittal, Sanjiv. and Rajat Gera. 2012. Relationship Between Service Quality Di Mensions And Behaviour Intentions : An Sem Study Of Public Sector Retail Banking Customers In India. Journal of Services Research. Vol. 12 No. 2, pp 147-171.

Misbach, Irwan., Surachman., Djumilah Hadiwidjojo., and Armanu. 2013. Islamic Bank Service Quality and Trust: Study on Islamic Bank in Makassar Indonesia. International Journal of Business and Management. Vol. 8 No. 5, pp 48-61. ISSN1833-3850 E-ISSN18338119. www.ccsenet.org/ijbm.

Mullins, John W et al. 2010. Marketing Management : A strategic Decision Making Approach. Seventh Edition. New York : McGraw-Hill.s

Nasab, Ahmad Akbari. and Ali Savand Roomi. 2012. An Analysis Of Effective Factors On Bank Interest Margin Rate (Case Study: ANSAR BANK). Interdisciplinary Journal Of Contemporary Research In Business.Vol. 4 No. 2, pp 1084-1090. ijcrb.webs.com.

Nakhchian, Ali., Ome Kolsom Zeraatgar Boorani., and Nagres Groji. 2012. Overall profitability of companies depending on optimal use of the marketing mix (4Ps) (McDonald's case study). Interdisciplinary Journal of Contemporary Research In Business. Vol. 4 No. 7, pp 876-889.ijcrb.webs.com. 
Oktarina, Uri. 2011. Persepsi Nasabah Tentang Sistem Penyampaian Jasa, Citra Merek dan Nilai Jasa Dalam Keputusan Penggunaan Jasa Bank Mandiri. Bandung : Unpad Bandung.

Parasuraman, A. 2010. Service productivity, quality and innovation. Implications for servicedesign practice and research. International Journal of Quality and Service Sciences. Vol. 2 No. 3, pp 277-286. www.emeraldinsight.com/1756-669X.htm.

Putra, I Wayan Jaman Adi. 2013. The Effect Of Quality And Service Value On Customer Loyalty. A Study on the Customers of Commercial Banks in Malang City. Interdisciplinary Journal Of Contemporary Research In Business. Vol. 5 No. 5, pp. 488-504. ijcrb.webs.com.

Putera. Aria Bima Pertama. 2012. Analisis Faktor Atribut Produk dan Harga Terhadap Keputusan Pembelian Produk Mobile Broadband di Kota Bandung. Unpad Bandung.

Prince, Panuel Rozario. and Zumman Bin Khaleq. 2013. Assessment of Gap Between Service Quality Expectation and Perception: A Study on the Walk-In Guests of Economic Hotels in Cox's Bazar Bangladesh. The IUP Journal of Marketing Management, Vol. XII No. 3 , pp 8-26.

Prihardianti, Andini. 2012. Analisis Pengaruh Kualitas Jasa dan Citra Perusahaan Terhadap Kepuasan Nasabah Pada Kantor Cabang Utama Bandung PT Bank Pembangunan Daerah Jawa Barat dan Banten Tbk. Bandung : Unpad Bandung.

Riduan. dan Engkos Achmad Kuncoro. 2011. Cara Menggunakan Dan Memakai Path Analysis. Bandung : Alfabeta

Rose, Peter S. and Sylvia C. Hudgins. 2010. Bank Management and Financial Service. Eight Edition. New York : McGraw-Hill.

Rahman, Muhammad Sabbir., Md Mahmudul Haque., and Abdul Highe Kan. 2012. A Conseptual Study on Consumers' Purchase Intention of Broadband Sevices : Service Quality and Experience Economy Persperctive. International Journal of Business and Management. Vol. 7 No.18, pp 115-129. ISSN1833-3850 E-ISSN1833-8119. www.ccsenet.org/ijbm.

Rattanaphan, Prasit. 2012. Consumer Attitudes toward the Corporate Image of Direct Selling Companies in Thailand. International Journal of e-Education, e-Business, e-Management and e-Learning. Vol. 2 No. 4, pp 290-293.

Raykov, Tenko and Marcoulides, George, A. 2006 "A First Course in Structural Equation Modeling" ( $2^{\text {nd }}$ ed), Lawrence Erlbaum Associates, Inc. New Jersey.

Raychaudhuri, P S. and Rahela Farooqi. 2013. Conceptualization and Measurement of Service Quality Dimensions in Business Markets: A Case of Indian IT Industry. The IUP Journal of Management Research. Vol. XII No. 1, pp 33-61.

Salam, Eman Mohamed Abd-El., Ayman Yehia Shawky., and Tawfik El-Nahas. 2013. The impact of corporate image and reputation on service quality, customer satisfaction and customer loyalty: testing the mediating role. Case analysis in an international service company. The Business and Management Review. Vol.3 No.2, pp 177-196.

Skevin, Petra. 2011. Commercial Real Estate Marketing-The Importance Of Office Location On Corporate Image. Prethodno Priopćenje Preliminary Communication. Vol. XXIII br. 2, str 227-246.

Sugiyono. 2012. Metode Penelitian Kuantitatif dan RandD. Bandung : Alfabeta.

Sugiyono. 2013. Statistik Untuk Penelitian. Bandung : Alfabeta.

Tantawi, Passent. and Amr Youssef. 2012. The importance of corporate social performance in place branding of retail banks in Egypt. African Journal of Economic and Management Studies.Vol. 3 No. 1, pp. 77-94. www.emeraldinsight.com/2040-0705.htm.

Veerasamy, Dayaneethie., Jeevarathnam Parthasarathy Govender., And Magalingam Atheeshey Pillay. 2013. Service Quality in Sport: A Higher Education Perspective. Journal of Economics and Behavioral Studies. Vol. 5 No. 2, pp. 99-105. ISSN: 2220-6140.

Vegholm, Fatima. 2011. Relationship Marketing And The Management Of Corporate Image In The Bank -SME Relationship. Management Research Review. Vol. 34 No. 3, pp. 325336. www.emeraldinsight.com/2040-8269.htm.

Weiwei, Tang. 2007. Impact Of Corporate Image And Corpirate Reputation On Customer Loyalty : A Review.Management Science and Engineering. Vol.1 No.2, pp 57-62. 
Yousapronpaiboon, Khanchitpol. and William C Johnson. 2013. A Comparison of Service Quality between Private and Public Hospitals in Thailand. International Journal of Business and Social Science. Vol. 4 No. 11, pp 176-184. www.ijbssnet.com.

Zeithaml, Valarie A,. Mary Jo Bitner. and Dwayne D Gremler. 2009. Service Marketing : Integrating Customer Focus Across the Firm. Fifth Edition. New York : McGraw-Hill

Sumber Website:

BPRKS. 2013. Bank Perkreditan Rakyat Karya Jatnika Sadaya. http://www.bprks.co.id diunduh 18 Februari 2013.

Bank Indonesia. 2013. Bank Indonesia. http://www.bi.go.id diunduh 18 Februari 2013.

Bank Indonesia. 2013. Bank Indonesia Statistik BPR Sub Menu Kredit. http://www.bi.go.id/biweb/Templates/Statistik/Statistik\%20BPR/SubMenu_Kredit_ID. asp $x$ ?NRMODE $=$ Published\&NRNODEGUID $=\{24475$ AE1-3B38-41E4-9F1B12B230B398F0 \} \&NRORIGINALURL=\%2fweb\%2fid\%2fStatistik $\% 2$ fStatistik $\% 2 b P e$ rbankan\%2fStatistik\%2bBPR\%2fKredit\%2f\&NRCACHEHINT=Guest diunduh 20 Agustus 2013.

Bank Indonesia. 2013. Bank Indonesia Statistik BPR Sub Menu Kelembagaan http://www.bi.go.id/biweb/Templates/Statistik/Statistik\%20BPR/SubMenu_Kelembaga an ID.asp $x$ ?NRMODE $=$ Published \&NRNODEGUID $=\{$ C0B82629-5AF9-415A-AF2BDF34ED4A17B9\}\&NRORIGINALURL=\%2fweb\%2fid\%2fStatistik\%2fStatistik\%2bP erbankan\%2fStatistik\%2bBPR\%2fKelembagaan\%2f\&NRCACHEHINT=Guest diunduh 20 Agustus 2013.

Bank Indonesia. 2014. Bank Indonesia Statistik Perbankan BPR Konvensional http://www.bi.go.id/id/statistik/perbankan/bpr-konvensional/totalaset/Default.aspx diunduh februari 2014.

Infobanknews. 2013 BPR Harus Serius Agar Tidak salah Urus. http://www.infobanknews.com/2013/04/bpr-harus-serius-agar-tak-salah-urus/ diunduh tgl 14 September 2013.

Bisnis Jabar. 2013. BI Atur Persaingan BPR dan Bank Jateng.http://www.Bisnis-jabar.com/biatur-persaingan-bpr-bank-jateng.htm : diunduh 18 Februari 2013.

Tempo. 2013. BPR Diminta Dilibatkan Dalam Penyaluran KUR. http://www.tempo.co/read/news/2010/11/23/087293786/BPR-Minta-DilibatkanDalam-Penyaluran-KUR diunduh 18 februari 2013. 